\title{
ATIVIDADES DOS SETORES DE EPIDEMIOLOGIA E ESTATISTICA NO CENTRO DE SAÚDE
}

\author{
José Maria Pacheco de Souza* \\ Victório Barbosa * \\ Ruy Laurenti * \\ Sabina Lea Gotlieb* \\ Maria Helena Silveira*
}

RSPU-B/292

\begin{abstract}
SouzA, J. M. P. de et al. - Atividades dos setores de epidemiologia e estatística no Ccntro de Saúde. Rev. Saúde públ., S. Paulo, 9:547-50, 1975.

RESUMo: São analisadas as atividades dos setores de epidemiologia e estatistica no centro de saúde. As atividades de epidemiologia têm como objetivo geral caracterizar as doenças e problemas de saúde da região. As de estatistica fornecem os dados necessários aos diversos setores do centro de saúde, incluindo-se os de epidemiologia e administração. São feitas sugestões para correção quantitativa e qualitativa dos dados obtidos. Algumas consideraçōes são feitas sobre a possibilidade de aproveitamento dos setores de epidemiologia e estatística para ensino e treinamento.
\end{abstract}

UNItermos: Serviços de saúde. Epidemiologia. Estatística vital. BioEstatistica.

\section{1 - INTRODUÇ ÃO}

No sistema de saúde do Estado de São Paulo, os centros de saúde desempenham papel fundamental; eles são os órgãos que estão em contato direto com a população, podendo ser encarados, inclusive, como pontes que ligam a comunidade com a administração central.

Assim, da mesma forma que é através dos centros de saúde que a Secretaria de Saúde oferece grande parte de seus serviços, tais centros devem ser, também, os elementos primários na obtenção das informações necessárias ao bom andamento das funçôes da Secretaria.

De fato, isto é previsto no item III do parágrafo único do artigo $20^{\circ}$ do Decreto
50.192 , de $13 / 8 / 68$, que dispõe sobre medidas para a reforma administrativa da Secretaria de Estado dos Negócios da Saúde; neste item são expressas as atividades de saúde pública em nível local, segundo quatro possíveis tipos de programas, constando, em três programas, "epidemiologia e estatística".

O objetivo deste trabalho é analisar as atividades dos setores de epidemiologia e estatística em um centro de saúde com área programática bem delimitada e bem definida. É baseado em projeto de programa a ser desenvolvido pelo Departamento de Epidemiologia da Faculdade de Saúde Pública da L'SP, junto ao Hospital

\footnotetext{
* Do Departamento de Epidemiologia da Faculdade de Saúde Pública da USP - Av. Dr Arnaldo, 715 - São Paulo, SP -- Brasil.
} 
SoUzA, J. M. P. de et al. - Atividades dos setores de epidemiologia e estatistica no Centro de Saúde. Rev. Saúde pübl., S. Paulo, 9:547-50, 1975.

Centro de Saúde de Cotia, o qual faz, também, considerações sobre atividades de ensino e treinamento.

\section{2 - SETOR DE EPIDEMIOLOGIA}

O objetivo geral destas atividades é caracterizar epidemiologicamente as doenças e os problemas de saúde da região. Será enfatizado o estudo e caracterização epidemiológica das doenças transmissíveis, devendo ser incluídos aspectos de nutrição. Parte dos dados utilizados serão fornecidos pelo setor de estatística, mas outros dados serão conseguidos diretamente pelo setor de epidemiologia, em caso de levantamentos específicos, por exemplo.

Especificamente, o setor de epidemiologia se dedicará: 1) ao estudo das endemias da região, em função do tempo, espaço e atributos da população; 2) ao estudo das epidemias, quando for o caso, estabelecendo as suas origens, modos de transmissão e dados sobre a população atacada, de acordo com seus principais atributos; 3) ao estudo de aspectos epidemiológicos obscuros de doenças mal conhecidas ou de outras já bem caracterizadas; 4) ao estudo de fatores de importância da estrutura epidemiológica da regiāo que possam influir sobre a ocorrência de doenças; 5) à avaliação dos resultados de programas ou campanhas profiláticas; 6) à realização de pesquisas epidemiológicas, de natureza variada, de interesse local.

Este conjunto de atividades que permite reunir a informação indispensável para, a todo momento, conhecer a história natural da doença, detectar ou prever qualquer alteração que possa ocorrer nos seus fatores condicionantes, com a finalidade de recomendar oportunamente, em bases sólidas, as medidas que conduzam à prevenção e/ou ao controle da doença, a curto, médio e longo prazo, é a chamada vigilância epidemiológica, função inerente ao setor de epidemiologia do centro de saúde.

\section{3 - SETOR DE ESTATISTICA}

Tem por objetivo coletar, criticar, apurar, analisar, interpretar e publicar dados, produzindo informação. É o principal alimentador dos outros setores, entre eles o de epidemiologia, já considerado, e o de administração, este último com estatísticas de serviço. Neste setor são encontrados dois sub-setores, o de estatística vital e o de bioestatística.

\section{1 - Estatística vital - trabalha} com dados de mortalidade e natalidade (nascidos vivos e nascidos mortos), que são os de principal interesse. A seguir, são examinados aspectos de mortalidade.

A coleta de dados deve ser feita periodicamente (mensal ou quinzenal), a partir dos atestados de óbitos registrados nos cartórios de registro civil do respectivo município, dos municípios vizinhos onde se suspeite convirjam os óbitos da região. A correção quantitativa dos dados será feita pela procura de óbitos não registrados, através de cemitérios clandestinos ou sepultamento em cemitérios oficiais de óbitos não registrados. Deve haver, ainda, a verificação dos casos registrados como "nascidos mortos" mas que, na verdade, foram de "nascidos vivos" que faleceram após alguns instantes de vida, devendo ser classificados, portanto, como óbitos; esta pesquisa é um processo contínuo, e será efetuada em hospitais, maternidades, etc., e principalmente junto às "curiosas" existentes na área. Há, ainda, o processo de correção qualitativa, a fim de melhorar a qualidade da informação do atestado de óbito: para cada atestado (ou amostra de atestados) será feita uma entrevista com o respectivo médico, a fim de conhecer a verdadeira causa básica e as associadas; o objetivo não é somente corrigir as informações, mas tam- 
SoUzA, J. M. P. de et al. - Atividades dos setores de ep:demiologia e estatistica no Centro de Saúde. Rev. Saíde pübl., S. Paulo, 9:547-50, 1975.

bém "educar" os médicos da área para se obter dados mais confiáveis. A apuração e apresentação dos dados de mortalidade devem ser feitas segundo idade, sexo, locais de ocorrência e residência, assistência médica e causas de morte (básica e associadas).

Quanto à natalidade. são pontos principais: a coleta de dados - deve ser periódica (mensal ou quinzenal), não só dos nascimentos registrados nos cartórios do respectivo município, mas. a exemplo da mortalidade. também dos municipios vizinhos e municípios para onde convirjam os nascimentos da região. Há a necessidade de se instituir a "declaração de nascimento", através de formulário próprio, onde constem: nome e idade dos pais, data do nascimento. sexo da crianca, peso ao nascer. tempo de gestação, ordem do nascimento. local. além do endereço do cartório onde deve ser feito o registro; tais formulários serão preenchidos no hospital ou em outro local onde se der o nascimento, sendo uma via entregue aos pais, para encaminhamento ao cartório; tais vias serão coletadas periodicamente nos cartórios e comparadas com as vias em poder dos hospitais e outros serviços, servindo de base para estimativas de sub-registro de nascimento. É claro que tais formulários devem ser entregues, também. a parteiras e "curiosas". para cobertura a mais completa possível dos eventos. A correção quantitativa dos dados de nascimento terá como base principal esta "declaração de nascimento". mas poderá ser suplementada por levantamentos feitos especificamente para este fim. A correção qualitativa, com implicações quantitativas na mortalidade, será feita pela identificação dos erros de diagnóstico quanto a "nascimento morto" e "nascimento vivo", junto aos hospitais. maternidades, parteiras e "curiosas", com entrevistas bem conduzidas. A apuração e apresentação dos dados de natalidade será feita segundo sexo, locais de residência e de ocorrência, assistência, idade da mãe, ordem do nas- cimento, peso da criança e duração da gestação.

\section{2 - Bioestatística - deve assesso-} rar os trabalhos conduzidos dentre os programas do centro de saúde, com papel fundamental na avaliação dos resultados; técnicas apropriadas de pesquisa de serviços de saúde podem ser utilizadas, quando pertinentes. A amostragem desempenhará função importante no delineamento de levantamentos epidemiológicos.

\section{4 - ENSINo E TREINAMENTO}

Alguns centros de saúde podem e devem ser utilizados como campo de treinamento em serviço para a própria Secretaria da Saúde e para ensino por entidades acadêmicas, tais como escolas de saúde pública e faculdades de medicina. Especificamente, no ensino de Estatística e Epidemiologia. se implantados os setores propostos, alunos poderão adquirir bastante conhecimentos e ser devidamente treinados, a qualquer instante que visitem o centro de saúde. sem necessidade de preparação prévia da instituição, de cada vez que recepcionar estudantes.

\section{5 - CONSIDERAÇOEES FINAIS}

Ao se analisar os setores de epidemiologia e de estatística de um centro de saúde, procurou-se lembrar pontos importantes destas atividades. chamando-se a atenção para aspectos metodológicos. E fundamental, no entanto. que não se perca de vista que tais setores são partes integrantes do centro de saúde. e. mais ainda, a serviço deste. $E$ que os centros de saúde pertencem a um sistema bastante amplo e complexo, o de Saúde, com um fim social muito importante, qual seja, o de melhorar e manter as condições de saúde da população, procurando. inclusive, diminuir a desigualdade existente entre diferentes estratos populacionais. 
SoUzA, J. M. P. de et al. - Atividades dos setores de epidemiologia e estatistica no Centro de Saúde. Rev. Saúde públ., S. Paulo, 9:547-50, 1975.

RSPU-B/292

SouzA, J. M. P. de et al, - [The activities of the sections of epidemiology and statistics in the Health Center]). Rev. Saúde públ., S. Paulo, 9:547-50, 1975.

SUMMARY: The functions of the sectors of epidemiology and statistics in a health center are analysed. The aim of the section of epidemiology is to characterize the diseases and health problems of the region. The section of statistics is the main feeder of data for epidemiology and other divisions. The paper points out directions for the quantitative and qualitative improvement of collected data. Considerations are made on the use of the sections for teaching and training purposes.

UNITERMS: Community health services. Epidemiology. Vital statistics. Biostatistics.

Recebido para publicação em 20/08/1975

A provado para publicação em 22/09/1975 